\title{
Standardized ileal digestible tryptophan requirement for broilers
}

\author{
J.W. Spek
}

Wageningen Livestock Research

CVB Documentation report nr. 65

June 2018

Wageningen Livestock Research

P.O. Box 338

$6700 \mathrm{AH}$ Wageningen

The Netherlands 


\section{ㄷ Federatie Nederlandse Diervoederketen 2017}

No part of this edition may be copied, photocopied, reproduced, translated or reduced to any electronic medium or machine-readable form, in whole or in part, without specific written permission of the Federatie Nederlandse Diervoederketen (info@diervoederketen.nl).

All copyrights and database rights with respect to this publication are expressly reserved. Nothing in this publication may be reproduced, copied, retrieved, made public or re-used or made available in any way whatsoever to third parties by way of printing, photocopying, microfilm or in any other way unless the Federatie Nederlandse Diervoederketen has given express written permission to do so. This publication has been compiled with great care; however, the Federatie Nederlandse Diervoederketen and Wageningen Livestock Research cannot be held liable in any way for the consequences of using the information in this publication. 


\section{Preface}

In 2017 a new Table has been introduced called; Table 'Standardized ileal digestibility of amino acids in feedstuffs for poultry' and has been described in the CVB Documentation report nr. 61. As a feed evaluation system has two pillars - the supply of nutrients by the diet on the one hand and the requirement for these nutrients by the animals on the other hand (both expressed in the same units) - it was also necessary to also update and express the amino acid requirements on a standardized ileal digestibility (SID) basis.

Therefore a large meta-analysis dataset was constructed from studies in which amino acid requirements in broilers were estimated. The SID amino acid concentrations of the diets used in the studies were recalculated based on the new CVB SID amino acid Table (CVB Documentation report nr. 61) and requirements of SID amino acids were subsequently estimated. The results of this meta-analysis for standardized ileal digestible tryptophan (SIDTRP) are presented in the present CVB Documentation report. Compared to the former CVB apparent faecal digestible TRP recommendation for broilers described in CVB Documentation report nr. 18 and published in 1996 the present established SID-TRP amino acid recommendations for broilers are:

1. Based on a substantial larger dataset of requirement studies

2. Based on studies with modern broiler types in the period $1990-2017$

3. Based on standardized ileal digestible amino acid values in feedstuffs instead of apparent faecal digestible amino acid values.

The in this report estimated requirement of SID-TRP will be incorporated in the Dutch CVB Tabellenboek Veevoeding Pluimvee 2018 and in the English version CVB Table Poultry Nutrition 2018.

This study was guided and assessed by the Technical Committee of CVB

Wageningen, June 2018

J.W. Spek 


\section{Members of the Technical Committee of the CVB}
M. Rijnen (chair)
J. Fledderus
B. Boswerger
A. Dijkslag
H. van Laar
K. Geerse
D. van Manen
J. van der Staak
H. Korterink
A. van de Ven
C. van Vuure
G. van Duinkerken

J.W. Spek
Nederlandse Vereniging Diervoederindustrie (Nevedi) Nederlandse Vereniging Diervoederindustrie (Nevedi) Nederlandse Vereniging Diervoederindustrie (Nevedi) Nederlandse Vereniging Diervoederindustrie (Nevedi) Nederlandse Vereniging Diervoederindustrie (Nevedi) Nederlandse Vereniging Diervoederindustrie (Nevedi) Overleggroep Producenten Natte Veevoeders (OPNV) Land- en Tuinbouworganisatie Nederland (LTO) Nederlandse Vereniging van Handelaren in Stro, Fourages en Aanverwante Producten (HISFA) Nederlandse Vereniging Diervoederindustrie (Nevedi) MVO, ketenorganisatie voor oliën en vetten Wageningen Livestock Research, Dept. Animal Nutrition, Wageningen

Wageningen Livestock Research, Dept. Animal Nutrition, Wageningen 


\section{Contents}

Table of Contents $\quad$ Page

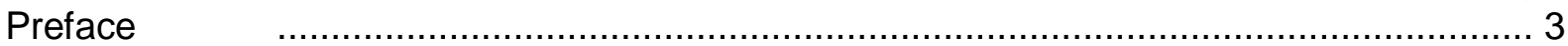

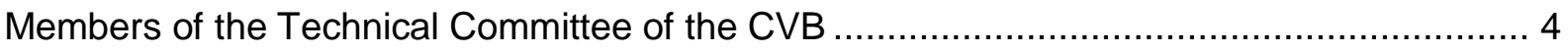

Contents $\quad$.

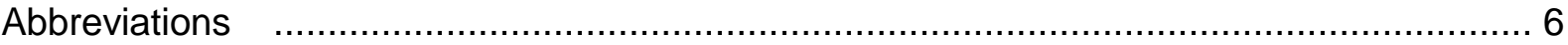

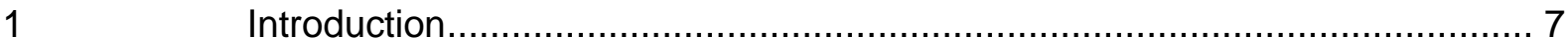

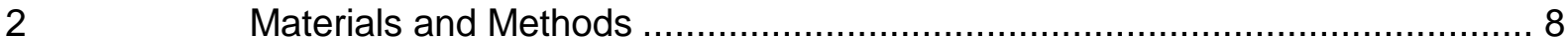

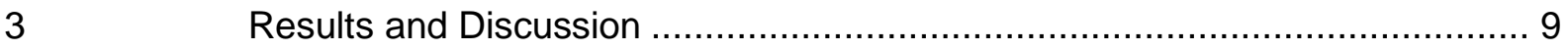

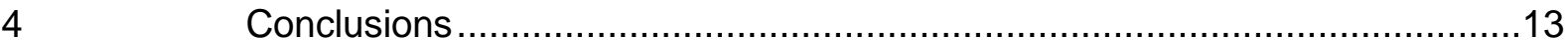

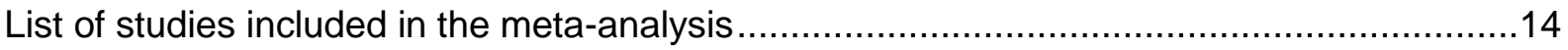

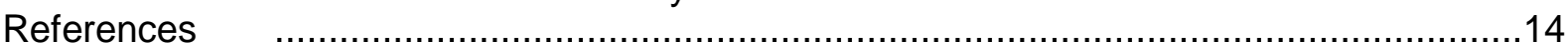

Appendix A. Relationship between dietary SID-TRP supply and performance parameters

FCR and BWG for the various titration trials. .........................................15

Appendix B. SID-TRP model estimates using the quadratic broken-line model for minimum

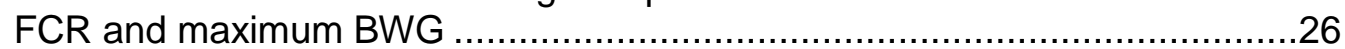




\section{Abbreviations}

$\begin{array}{ll}\text { AA } & \text { Amino acids } \\ \text { AFD } & \text { Apparent faecal digestible } \\ \text { ARG } & \text { Arginine } \\ \text { BWG } & \text { Body weight gain } \\ \text { CP } & \text { Crude protein } \\ \text { FCR } & \text { Feed conversion ratio } \\ \text { ILE } & \text { Isoleucine } \\ \text { LYS } & \text { Lysine } \\ \text { ME } & \text { Metabolic energy } \\ \text { MET } & \text { Methionine } \\ \text { M+C } & \text { Methionine plus Cysteine } \\ \text { N } & \text { Number } \\ \text { R } & \text { Coefficient of determination } \\ \text { Req } & \text { Requirement } \\ \text { SID } & \text { Standardized ileal tract digestible } \\ \text { Std. Dev. } & \text { Standard deviation } \\ \text { Std. Err. } & \text { Standard error } \\ \text { THR } & \text { Threonine } \\ \text { TRP } & \text { Tryptophan } \\ \text { VAL } & \text { Valine }\end{array}$




\section{Introduction}

In 2012 a large meta-analysis was carried out by Veldkamp and others in order to determine the dietary requirements for standardized ileal tract digestible (SID) amino acids (AA) for broilers. This study resulted in a report published by Veldkamp et al. (2016). Before the start of this meta-analysis by Veldkamp et al. another large meta-analysis was carried out in order to determine the SID-AA levels for the various feed ingredients. This meta-analysis resulted in a CVB table with SID-AA concentrations for the various feed ingredients and this Table was used by Veldkamp et al. (2016) in order to recalculate the dietary SID-AA levels for the individual AA titration studies in order to estimate AA requirements. However, in 2017 this CVB Table has been updated with new data published in the years between 2012 and 2017 as there were questions about the SID cysteine digestibility value for soybean meal. As a result, not only the SID-AA values for soybean meal have been updated but also for other feedstuffs. As a consequence it was necessary to recalculate all the diets used in the AA titration studies that Veldkamp et al. (2016) used to determine AA requirements. In this CVB documentation report the results of estimated dietary SID tryptophan (SID-TRP; \%) requirements are presented that are based on the new Table values as presented in CVB documentation report nr. 61. Furthermore, the dataset used by Veldkamp et al. has been extended with new studies that were not included in the study of Veldkamp et al.. This resulted in a dataset that is substantially larger than the dataset used by Veldkamp. The SIDTRP requirements of the individual titration trials were estimated using a quadratic broken line model. This model was also used in estimation of SID-lysine requirements in the individual lysine titration trials as described in CVB documentation report nr. 62. 


\section{Materials and Methods}

Tryptophan titration studies were selected from literature $(1990-2017)$ in which only the dietary TRP content was varied by means of addition of graded levels of dietary synthetic TRP. Furthermore, only those titration studies were selected in which non-test apparent digestible amino acid levels of the basal diet (diet with the lowest TRP content) did not come below $10 \%$ of the recommended CVB (2012) levels and where dietary digestible TRP levels of the basal diets where at least $20 \%$ below the recommended CVB (2012) level.

Furthermore, performance characteristics such as body weight gain (BWG: g/d) and feed conversion ratio (FCR; $g$ feed : $g$ BWG) had to be recorded and information with respect to dietary composition, sex, age of the broilers and duration of the experiment had to be provided in the studies.

Requirements were estimated using a quadratic broken-line model. The quadratic broken line model is as follows:

If $(\operatorname{SID}-T R P(\%)<R)$ then BWG or FCR $=\mathrm{L}+\mathrm{U} \times(\mathrm{R}-\mathrm{SID}-\mathrm{TRP})^{\wedge}$; Else $B W G$ or $F C R=L+U \times 0$;

Where:

$\mathrm{L}=$ plateau value for $\mathrm{BWG}$ or $\mathrm{FCR}$

$\mathrm{R}=$ break-point value for SID-TRP (\%)

$U$ = slope value, representing the increase in BWG or decrease in FCR per unit increase in dietary SID-TRP.

As TRP requirements are normally expressed as a percentage of lysine (LYS) requirement the estimated SID-TRP requirements of the individual TRP titration trials were expressed as a percentage of SID-LYS level as well. The SID-LYS level was in a number of cases the SIDLYS level used in the TRP titration studies. However, in a number of cases the SID-LYS levels used in the TRP titration studies were larger than the SID-LYS requirements as predicted from the factors mean age of the birds and the dietary ME value as described in the prediction formulas F.5. and F.9. in the CVB documentation report nr. 62 . in those cases where the SID-LYS levels used in the TRP titration studies were larger than the SID-LYS requirements as predicted from the prediction formula in the CVB documentation report nr. 62 the estimated SID-LYS requirement levels using formulas F.5. (for BWG) and F.9. (for FCR) were used for the calculation of the SID-TRP: SID-LYS requirement ratios (SIDTRP:LYS) of the individual experiments.

Via the PROC MIXED procedure of SAS the estimated SID-TRP:LYS requirements for BWG and FCR were regressed against factors such as age, sex and the dietary factors CP, ME and $\mathrm{CP}$ : ME ratio with study effect included as a random factor. Furthermore, the estimated SID-LYS requirement levels were also used to calculate ratios of other non-test SID-AA with the estimated requirement SID-LYS levels and it was checked whether some of the non-test SID AA were negatively affecting the estimated SID-TRP:LYS levels. 


\section{Results and Discussion}

In Table 1 a summary of the total dataset is given. The dataset consisted of 7 studies with in total 12 titration trials and 75 observations.

Table 1. Summary of the total dataset

\begin{tabular}{lrrrrr}
\hline & N & Mean & $\begin{array}{r}\text { Std } \\
\text { Dev }\end{array}$ & Minimum & Maximum \\
\hline ME Recalculated (kcal/kg) & 75 & 3180 & 130.9 & 3008 & 3572 \\
ME Publication (kcal/kg) & 75 & 3247 & 117.7 & 3086 & 3400 \\
CP Recalculated (\%) & 75 & 22 & 1.4 & 18 & 23 \\
CP Publication (\%) & 75 & 22 & 2.2 & 17 & 25 \\
Year & 75 & 2002 & 2.0 & 1999 & 2005 \\
Starting age (d) & 75 & 5 & 5.4 & 1 & 20 \\
Duration (d) & 75 & 17 & 2.7 & 13 & 20 \\
finishing age (d) & 75 & 21 & 5.7 & 18 & 40 \\
Mean age (d) & 75 & 13 & 5.4 & 10 & 30 \\
BWG (g/d) & 75 & 28.9 & 21.12 & 4.1 & 93.0 \\
FCR & 75 & 1.831 & 0.6978 & 1.304 & 5.260 \\
\hline
\end{tabular}

In Appendix A for each titration trial the relationship between dietary SID-TRP supply and FCR between dietary SID-TRP and BWG is presented graphically together with the estimated SID-TRP requirements. In Appendix B the estimated quadratic broken-line model parameters for each titration trial is given.

It was observed that for trial 2 (study of Fatufe et al. 2005), the estimated SID-TRP requirement for BWG was substantially larger than would be expected from a visual interpretation of the curve. This overestimation of the SID-TRP requirement in trial 2 could be avoided by removing the first 5 observations leaving still some 5 observations on which the curve fitting could be carried out. Removing these 5 observations resulted in a substantially lower estimated SID-TRP requirement which closely agreed with the SID-TRP requirement as would be judged from a visual interpretation of the relationship between SID-TRP supply and BWG as shown in Appendix A in trial $2 b$. The effect of removing the lowest dietary SIDTRP levels on estimated SID-TRP requirements was also investigated for the other titration trials. In Appendix A and Appendix B the titration results with all observations are represented with the letter ' $a$ ' whereas the titration results in which the lowest SID-TRP level(s) was/were removed before estimation of the SID-TRP requirement are represented with the letter 'b'. In some cases (trials 9, 10 and 11) it was not possible to remove the lowest dietary SID-TRP level as it resulted in too few observations for a successful model estimation of SID-TRP requirements. Comparing results ' $a$ ' with results ' $b$ ' for both BWG and FCR it was observed that in two cases (trials 7 and 8 ) removal of the lowest SID-TRP observation resulted in a situation in which no unique SID-TRP value could be estimated. It was judged that only for trial 2 it was justified to remove the lowest SID-TRP values in order to estimate SID-TRP values for BWG whereas in all other situations SID-TRP requirement estimates for BWG and FCR should be based on all observations.

Furthermore, for 2 titration trials for FCR and 2 titration trials for BWG it was not possible to estimate reliable or unique SID-TRP requirements.

The estimated SID-TRP:LYS requirement ratios for BWG and FCR were not significantly related to sex, age and the dietary factors ME, CP or CP : ME ratio. Furthermore, there was a significant $(P=0.004)$ effect of the dietary SID-MET+CYS : SID-LYS ratio on estimated SIDTRP:LYS requirement ratios for BWG as shown in Figure 1. However, the relationship between dietary SID-M+C : SID-LYS ratio and estimated SID-TRP:LYS requirement ratios for minimum FCR was not significant $(P=0.110)$ and was highly dependent on one very 
influential observation (observation from study of Corzo et al., 2005). Furthermore, even after removal of the observation of the study of Corzo et al. (2005), the positive relationship between dietary SID-MET+CYS : SID-LYS ratio and estimated SID-TRP:LYS ratio for BWG remained positive and significant $(P=0.041)$.

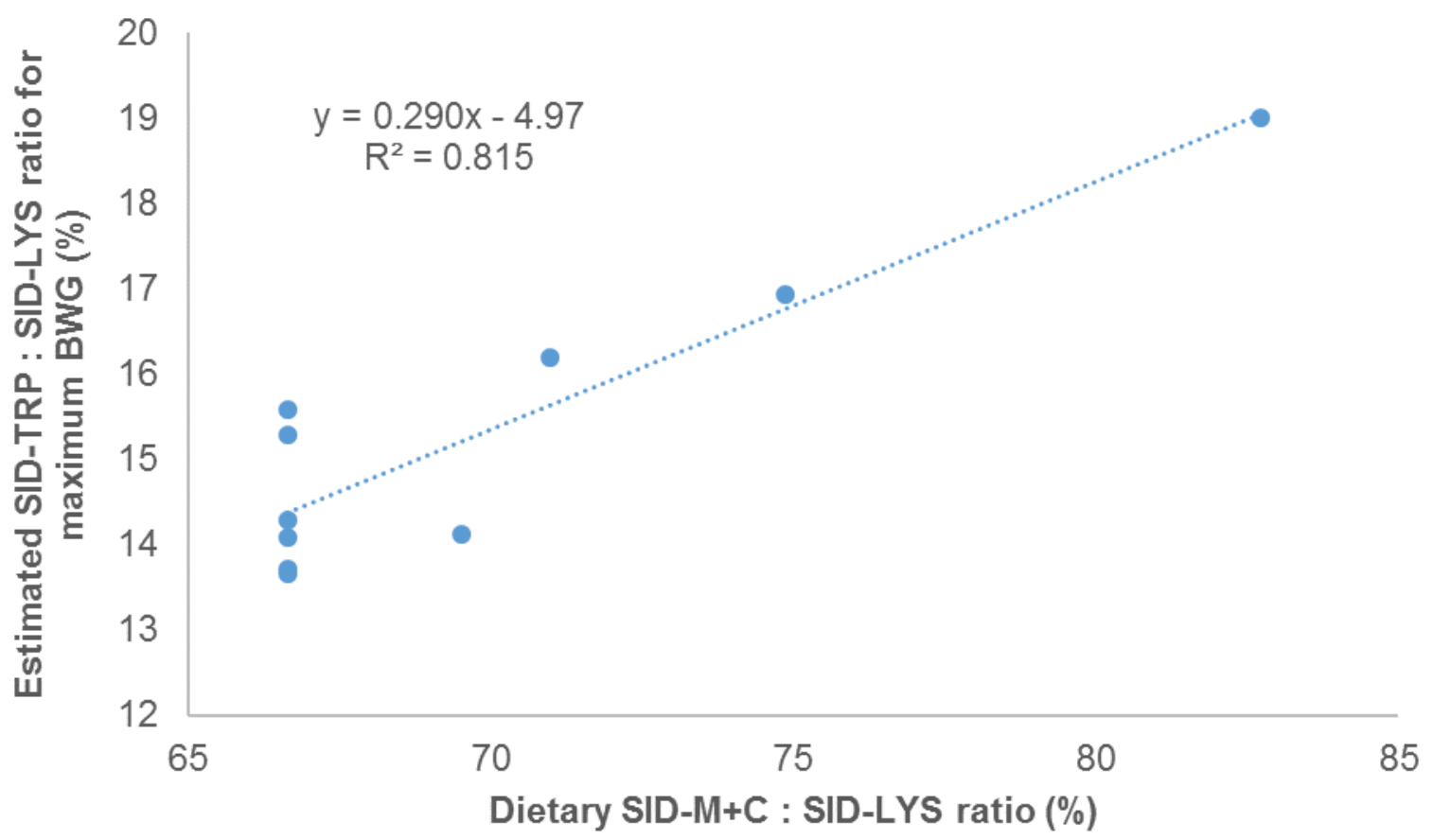

Figure 1. Relationship between dietary SID-M+C : SID-LYS ratio (\%) and estimated SIDTRP : SID-LYS requirement ratio for maximum BWG (\%).

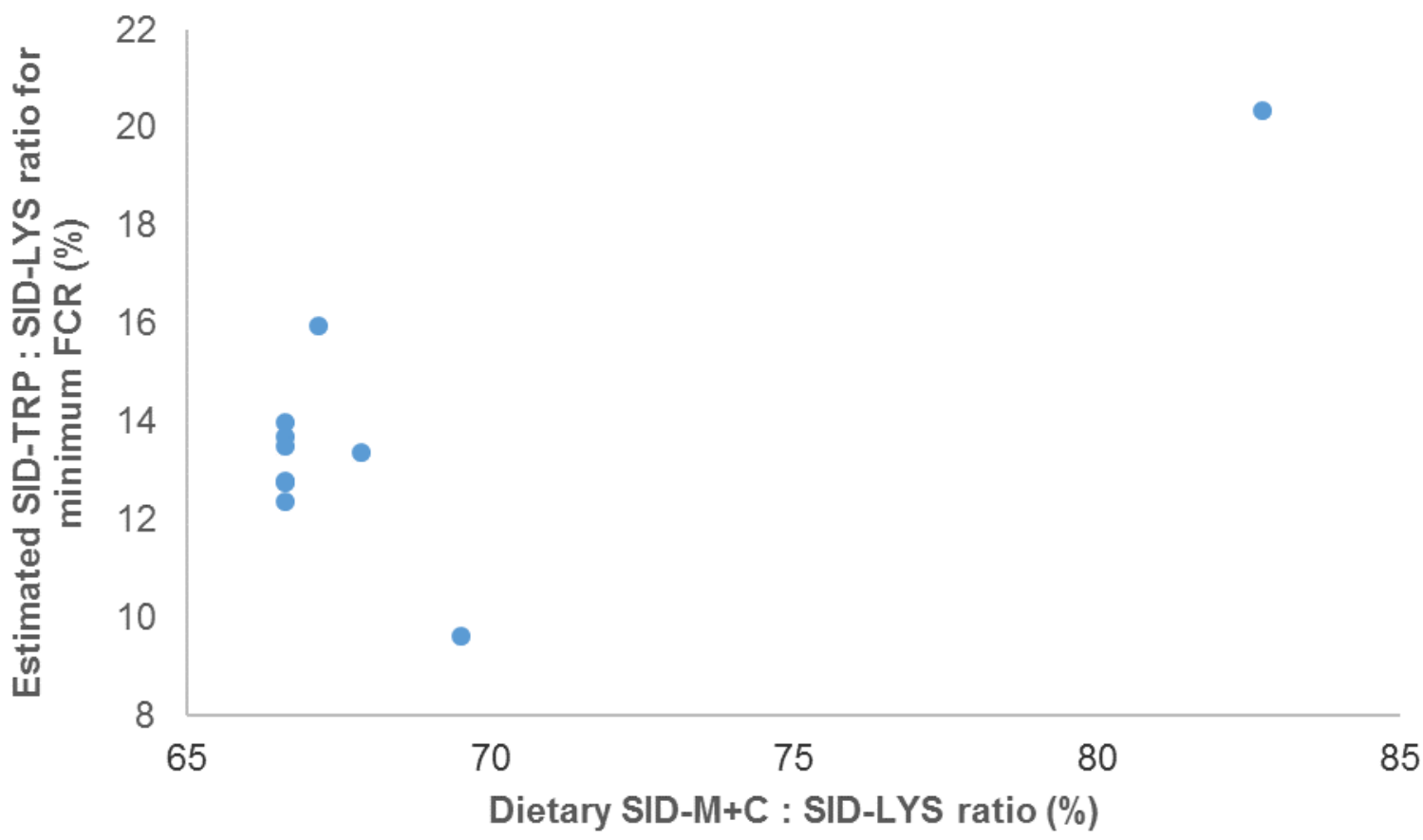

Figure 2. Relationship between dietary SID-M+C : SID-LYS ratio (\%) and estimated SIDTRP : SID-LYS requirement ratio for minimum FCR (\%). 
From a physiological point of view it is difficult to explain the positive effect of dietary SID$\mathrm{M}+\mathrm{C}$ on the estimated requirement of SID-TRP. It cannot be explained by the fact that dietary SID-M+C was offered in sub-optimal concentrations as there were two observations with SID-M+C:SID-LYS ratios higher than $75 \%$ that strongly determined this positive relationship.

Assuming an optimal SID-M+C:SID-LYS ratio of $73 \%$ and using the regression equation shown in Figure 1 on the relationship between dietary SID-M+C : SID-LYS ratio (\%) and estimated SID-TRP : SID-LYS ratio (\%) for maximum BWG (\%) it can be calculated that the optimal dietary SID-TRP:SID-LYS according to the relationship shown in Figure 1 is $16 \%$.

The average estimated SID-TRP:SID-LYS requirement ratios for the 10 SID-TRP:LYS requirement observations for BWG and FCR were:

SID-TRP:LYS for BWG $=15.3 \pm 1.71 \%$ (average \pm Std. Dev.)

SID-M+C:LYS for FCR $=13.8 \pm 2.78 \%$ (average \pm Std. Dev.)

Furthermore, there was one outlier SID-TRP requirement estimate that deviated more than two standard deviations from the average estimated SID-TRP requirement estimates. This was the observation from the study of Corzo et al. (2005).

When removing this outlier value the average estimated SID-TRP:SID-LYS requirement ratios for the remaining 9 FCR and BWG observations were:

SID-TRP:SID-LYS for BWG $=14.9 \pm 1.17 \%$ (average \pm Std. Dev. $)$

SID-TRP:SID-LYS for FCR $=13.1 \pm 1.67 \%$ (average \pm Std. Dev.)

There was one study that contained four titration trials whereas some studies contained only one titration trial. This results in average calculated SID-TRP:SID-LYS requirement ratios for $B W G$ and FCR that are strongly influenced by the study containing four titration trials. In order to weigh the estimated SID-TRP:SID-LYS ratios from each study equally it is possible to take into account the effect of study. When this was done (using the PROC MIXED procedure of SAS and by including study as a random effect in the model) the estimated SID-TRP:SID-LYS requirement ratios for BWG and FCR became:

SID-TRP:SID-LYS for BWG $=15.8 \pm 0.76 \%$ (estimate \pm Std. Err)

SID-TRP:SID-LYS for FCR $=14.3 \pm 1.46 \%$ (estimate \pm Std. Err)

In case the results of the study of Corzo et al. (2015) were not included the estimated SIDTRP:SID-LYS requirement ratios for BWG and FCR corrected for study effect were:

SID-TRP:SID-LYS for BWG $=15.2 \pm 0.53 \%$ (estimate \pm Std. Err)

SID-TRP:SID-LYS for FCR $=13.1 \pm 0.98 \%$ (estimate \pm Std. Err)

In Table 2 the dietary non-test SID-AA : estimated SID-LYS requirements ratios using the quadratic broken-line procedure for FCR and BWG are given together with the recommended CVB apparent fecal digestible (AFD) ratios. Results in Table 2 show that at least in some of the trials some non-test AA levels could have had a negative impact on estimated SID-TRP requirement levels as a comparison between recommended CVB ratios and minimal ratios for both FCR and BWG observed in this study show. However, a visual inspection of graphs in which the various AA:LYS ratios were plotted against estimated SIDTRP:SID-LYS requirements did not show any study in which the estimated SID-TRP requirements substantially differed from the rest of the SID-TRP requirement estimates combined with suboptimal low ratios of non-test AA:LYS ratios of M+C:LYS, THR:LYS ILE:LYS, ARG:LYS en VAL:LYS. 
Table 2. Dietary non-test SID-AA : SID-LYS ratios.

\begin{tabular}{|c|c|c|c|c|c|c|c|c|c|}
\hline \multirow[b]{2}{*}{ Ratio } & \multirow{2}{*}{$\begin{array}{l}\text { Rec. } \\
\text { CVB } \\
\text { AFD } \\
\text { ratio }\end{array}$} & \multicolumn{4}{|c|}{ FCR } & \multicolumn{4}{|c|}{ BWG } \\
\hline & & Mean & St.dev & Min & Max & Mean & St.dev & Min & Max \\
\hline M+C:LYS & 73 & 69 & 4.8 & 67 & 83 & 69 & 4.9 & 67 & 83 \\
\hline THR:LYS & 65 & 65 & 4.0 & 57 & 69 & 65 & 3.8 & 58 & 70 \\
\hline ILE:LYS & 66 & 61 & 5.7 & 57 & 73 & 62 & 6.0 & 57 & 73 \\
\hline ARG:LYS & 105 & 112 & 16.5 & 83 & 144 & 112 & 16.3 & 84 & 144 \\
\hline VAL:LYS & 80 & 76 & 6.3 & 72 & 92 & 77 & 7.4 & 72 & 97 \\
\hline
\end{tabular}




\section{Conclusions}

Based on the results of this study it is concluded that it is most prudent to base dietary SIDTRP:LYS requirement ratios on the complete dataset of SID-TRP trials and correct for a (random) study effect. This results in the following SID-TRP:LYS requirements:

SID-TRP:LYS for BWG $=15 \%$

SID-TRP:LYS for FCR $=13 \%$ 


\section{List of studies included in the meta-analysis}

Baker, D. H., A. B. Batal, T. M. Parr, N. R. Augspurger, and C. M. Parsons. 2002. Ideal ratio (relative to lysine) of tryptophan, threonine, isoleucine, and valine for chicks during the second and third weeks posthatch. Poultry Science 81(4):485-494.

Corzo, A., M. T. Kidd, J. P. Thaxton, and B. J. Kerr. 2005. Dietary tryptophan effects on growth and stress responses of male broiler chicks. British Poultry Science 46(4):478-484.

De Castro, A. J., P. C. Gomes, J. M. R. Pupa, H. S. Rostagno, L. F. T. Albino, and A. H. Nascimento. 2000. Tryptophan Requirement for Broilers from 1 to 21 Days of Age. Revista Brasileira de Zootecnia 29(6):1743-1749.

Fatufe, A. A., F. Hirche, and M. Rodehutscord. 2005. Estimates of individual factors of the tryptophan requirement based on protein and tryptophan accretion responses to increasing tryptophan supply in broiler chickens 8-21 days of age. Archives of Animal Nutrition 59(3):181-190.

Mack, S., D. Bercovici, G. De Groote, B. Leclercq, M. Lippens, M. Pack, J. B. Schutte, and S. Van Cauwenberghe. 1999. Ideal amino acid profile and dietary lysine specification for broiler chickens of 20 to 40 days of age. British Poultry Science 40(2):257-265.

Rosa, A. P., G. M. Pesti, H. M. Edwards Jr, and R. Bakalli. 2001. Tryptophan requirements of different broiler genotypes. Poultry Science 80(12):1718-1722.

Shan, A. S., K. G. Sterling, G. M. Pesti, R. I. Bakalli, J. P. Driver, and A. A. Tejedor. 2003. The influence of temperature on the threonine and tryptophan requirements of young broiler chicks. Poultry Science 82(7):1154-1162.

\section{References}

Blok and Dekker. 2017. Table 'Standardized ileal digestibility of amino acids in feedstuffs for poultry'. CVB Documentation report nr. 61.

Spek, J.W. 2018. Standardized ileal digestible lysine requirement for broilers. CVB Documentation report n. 62.

Veldkamp, T., J.W. van Riel, R.A. Dekker, S. Khalaji, V. Khaksar, H. Hashemipour, M.M. van Krimpen, and M.C. Blok. 2016. Estimating requirement values for apparent faecal digestible and standardised ileal digestible tryptophan in broilers by a meta-analysis approach. 


\section{Appendix A. Relationship between dietary SID-TRP supply and performance parameters FCR and BWG for the various titration trials.}

On the x-axis of the Figures the dietary TRP concentration (\%) is given and on the $y$-axis of the Figures the FCR (left hand Figures) and BWG (right hand figures) are given. The closed circles are the observed values and the ' $c$ ' symbols are the fitted values. The letter 'a' behind the trial number (shown in the first column) means the model is fitted on all observations whereas the letter 'b' behind the trial number (shown in the first column) means the model is fitted on all observations except the observations(s) with the lowest dietary SID-TRP level(s). If no letter is shown behind the trial number it means that the model is fitted based on all observations of the trial.

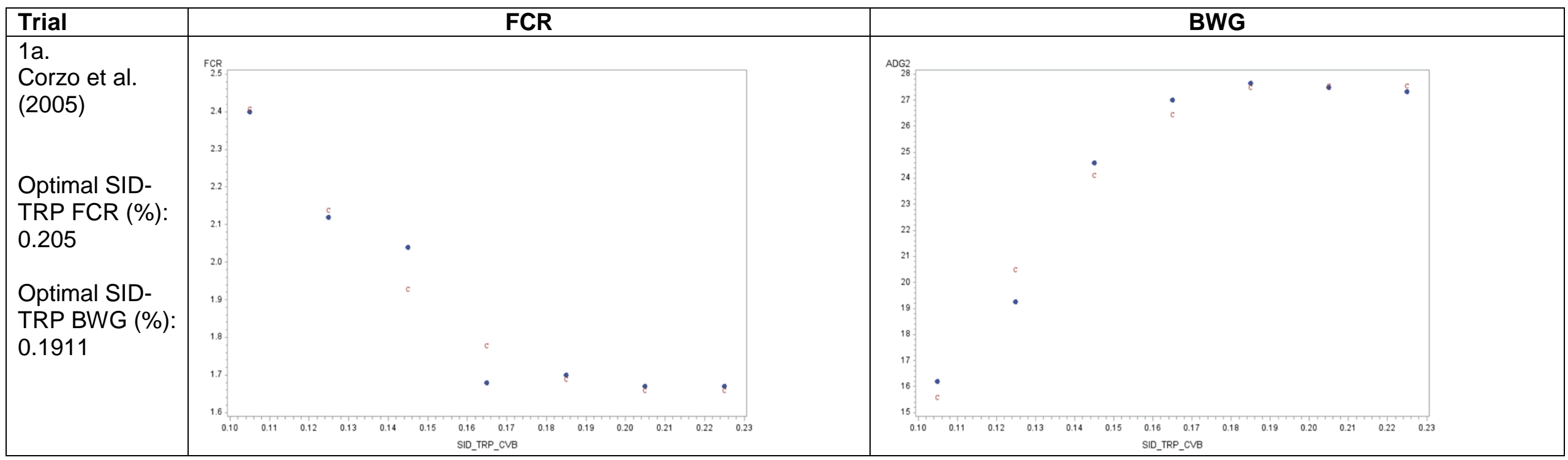




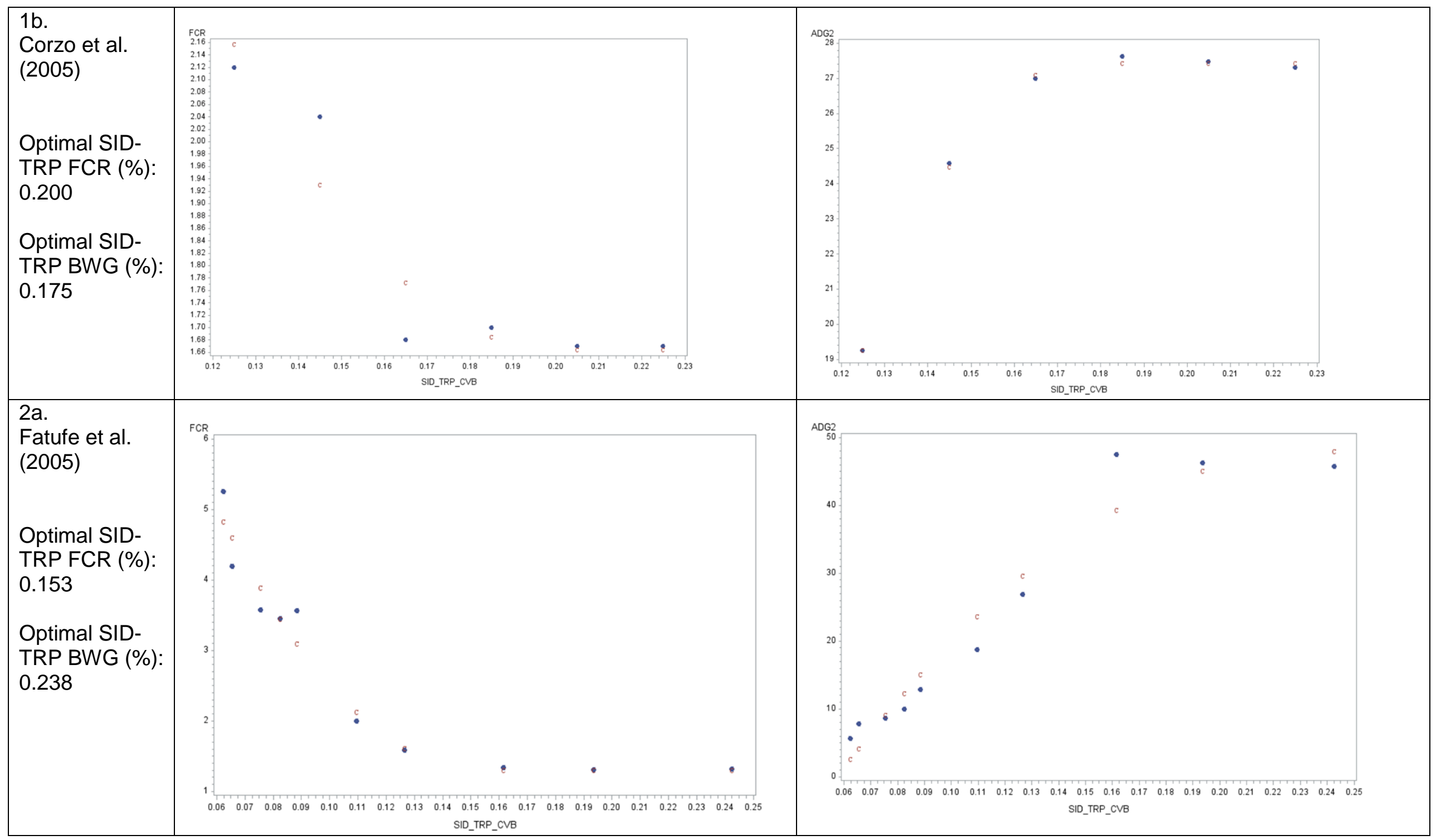




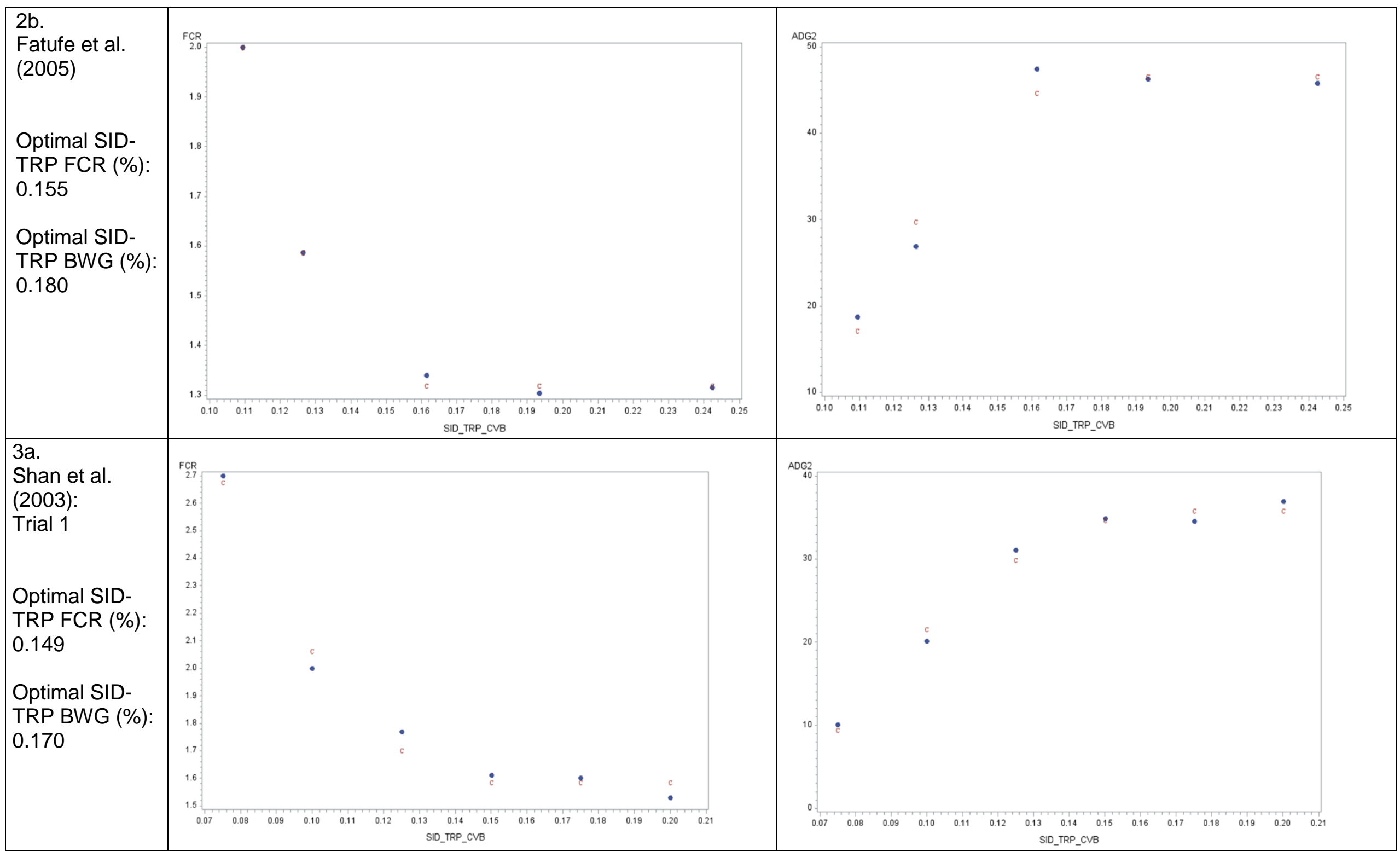




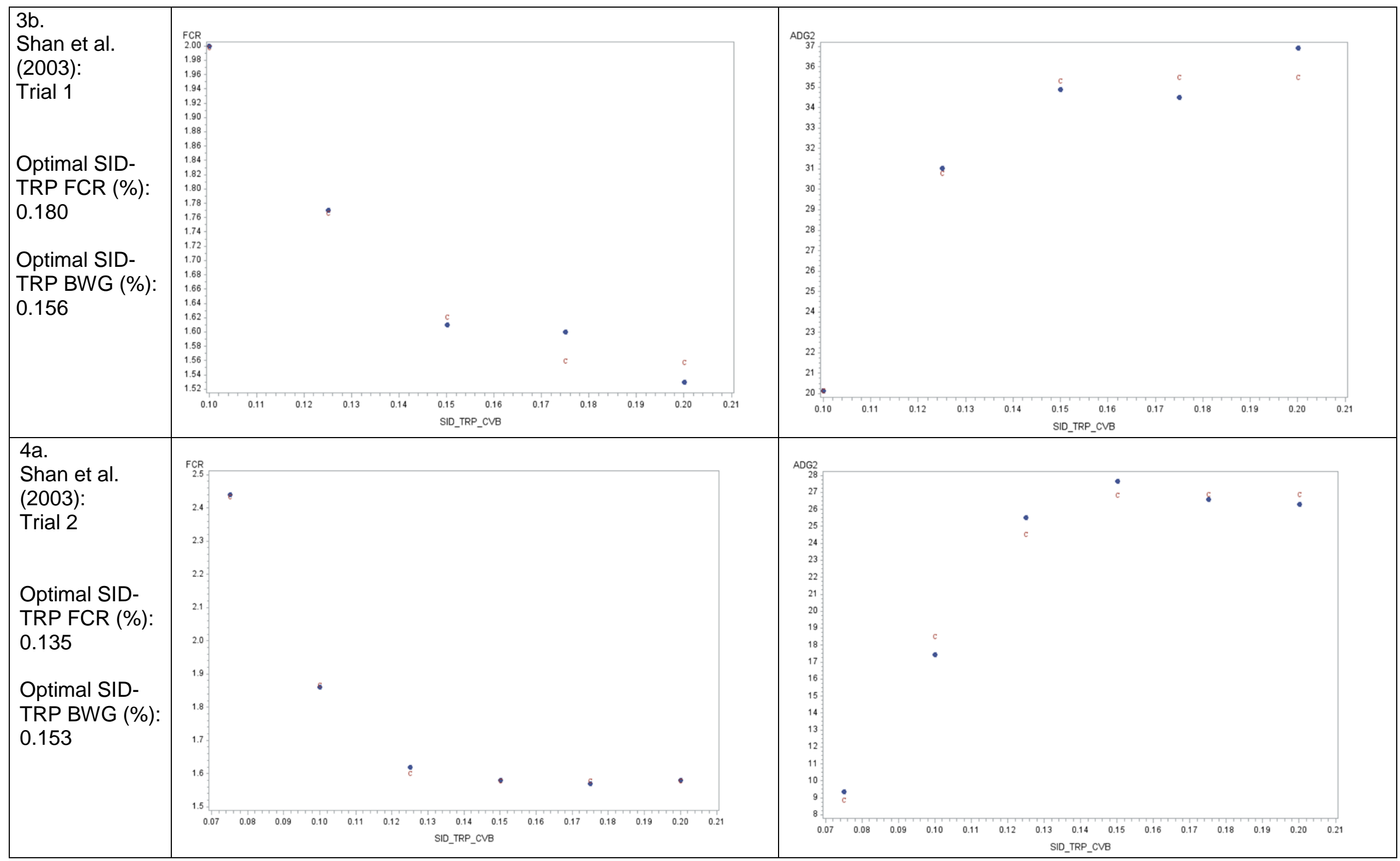




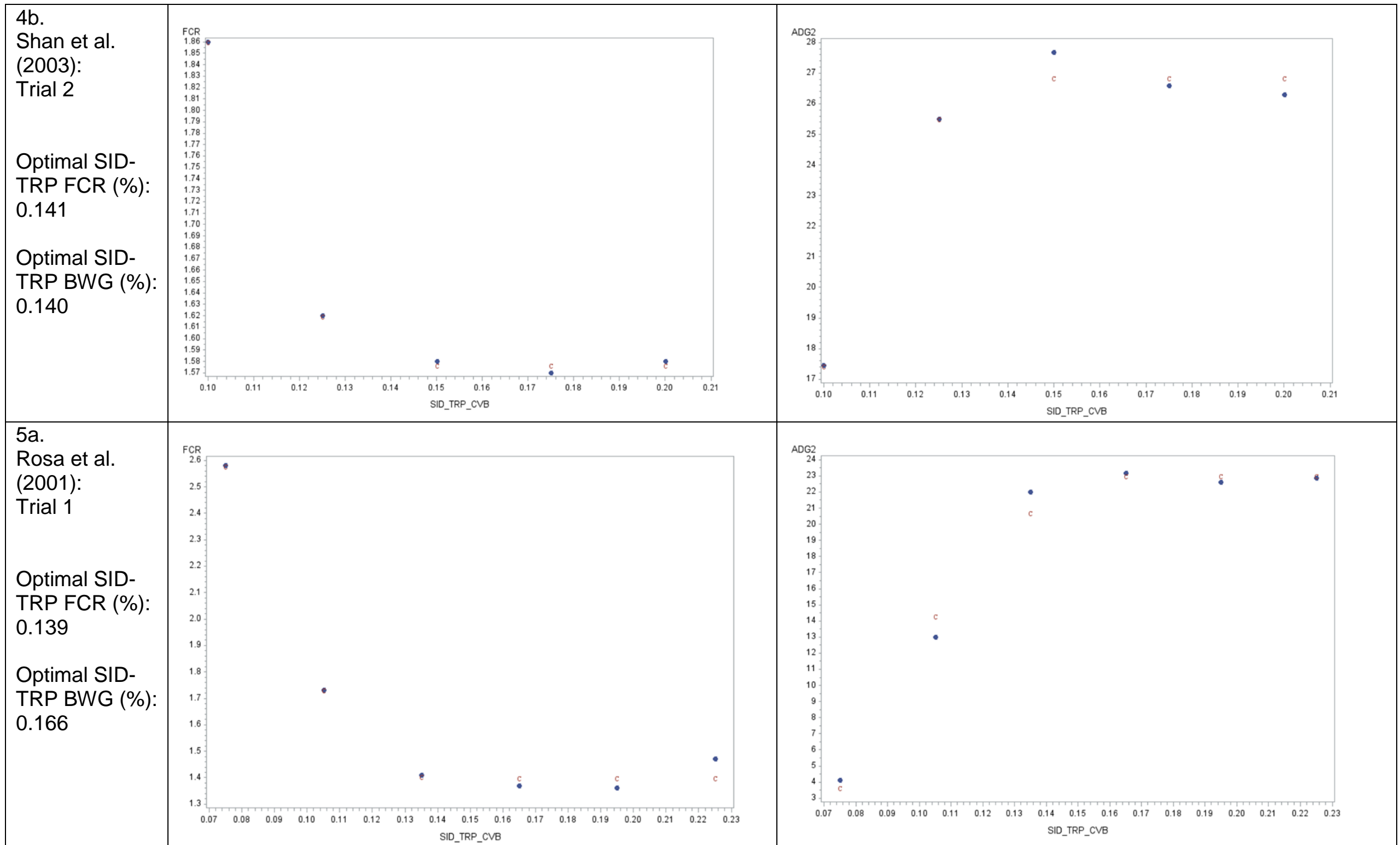




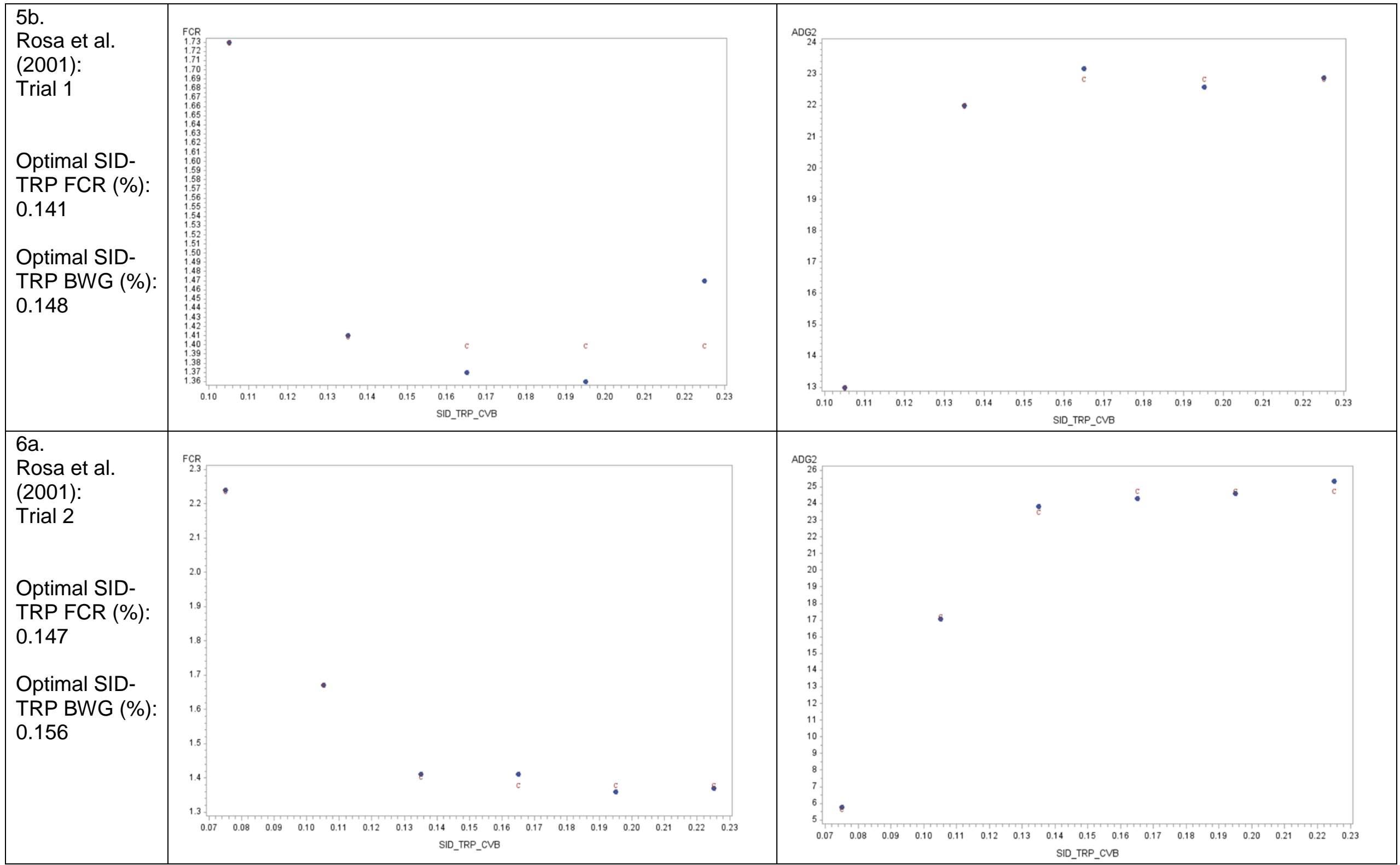




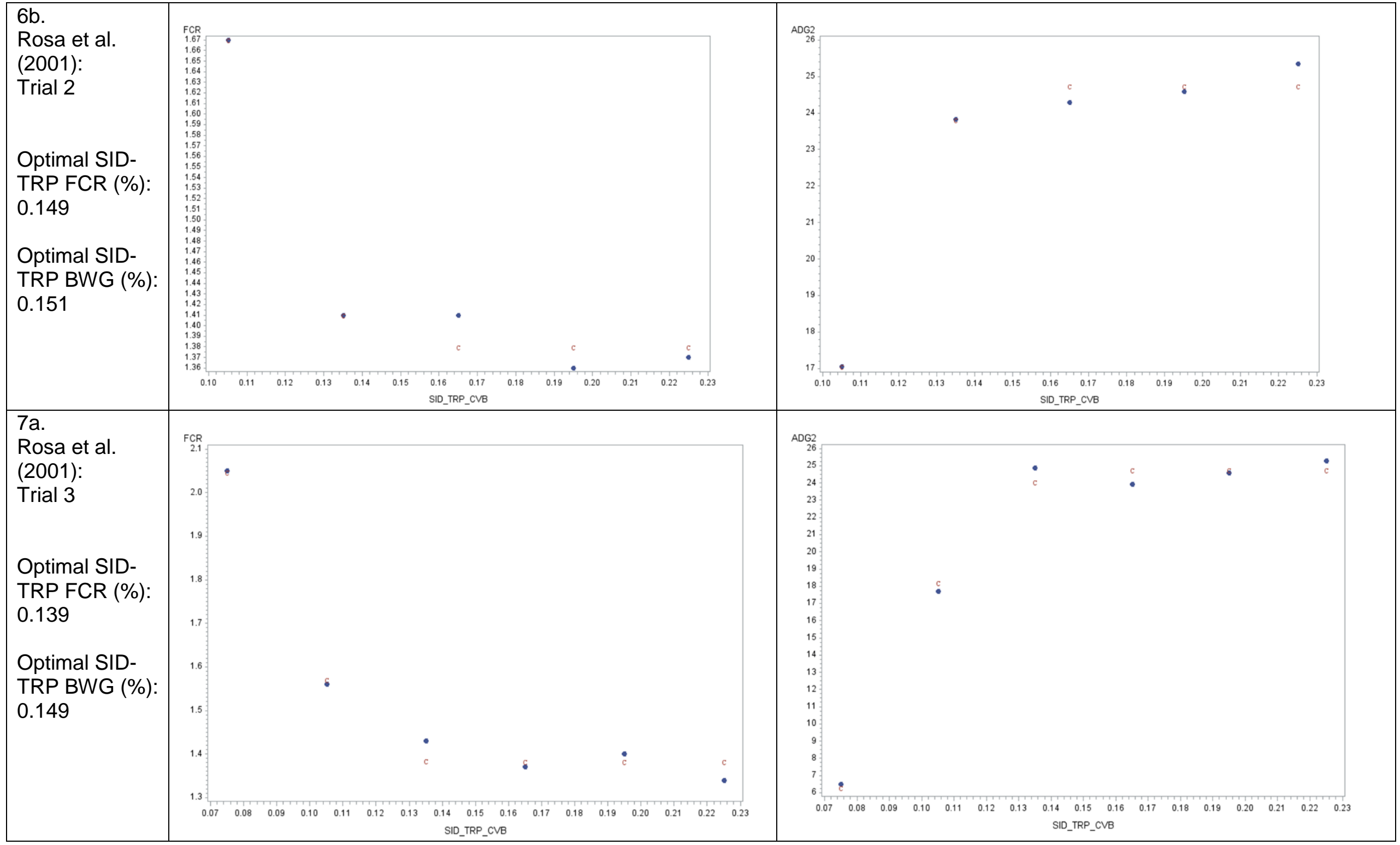




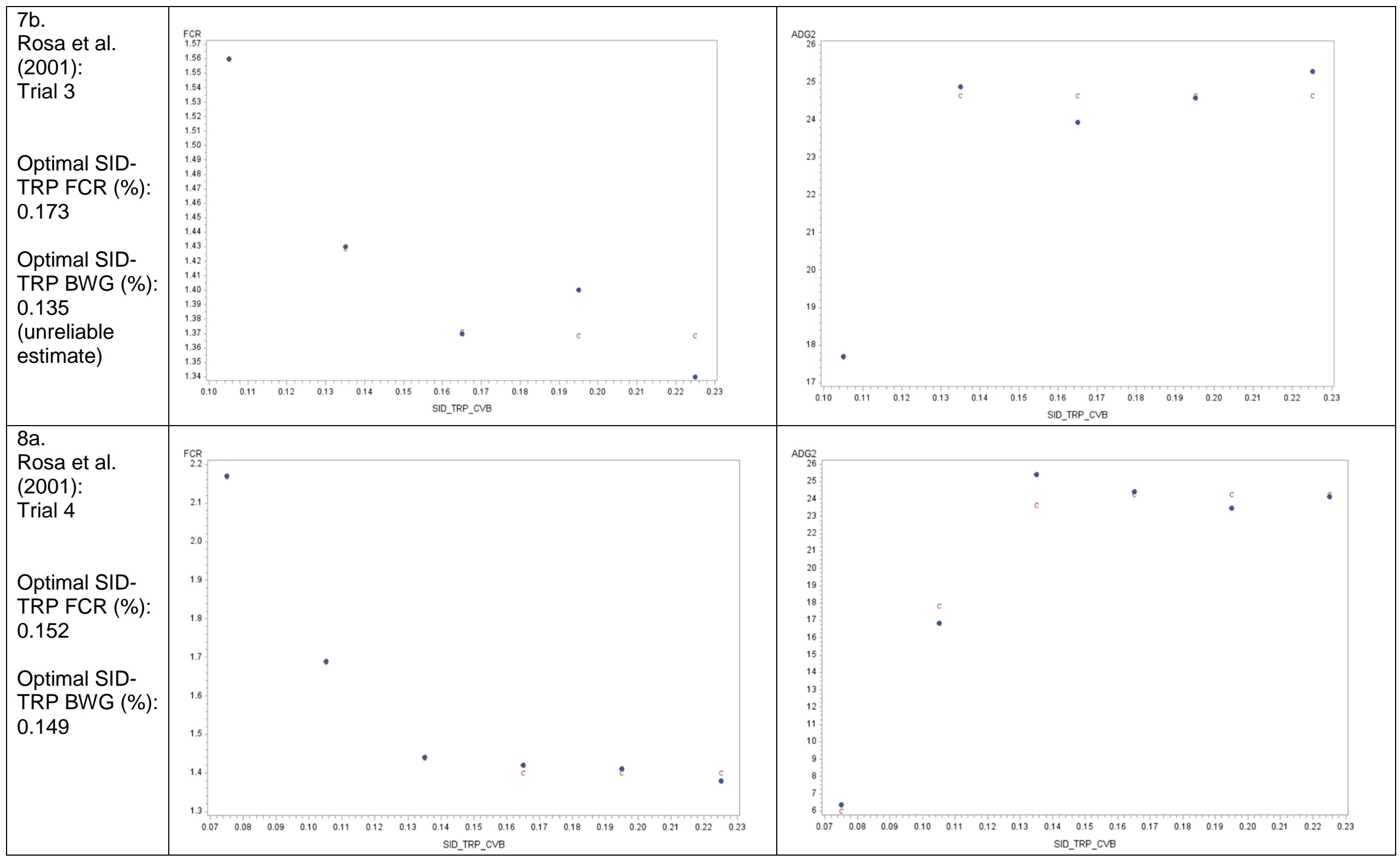




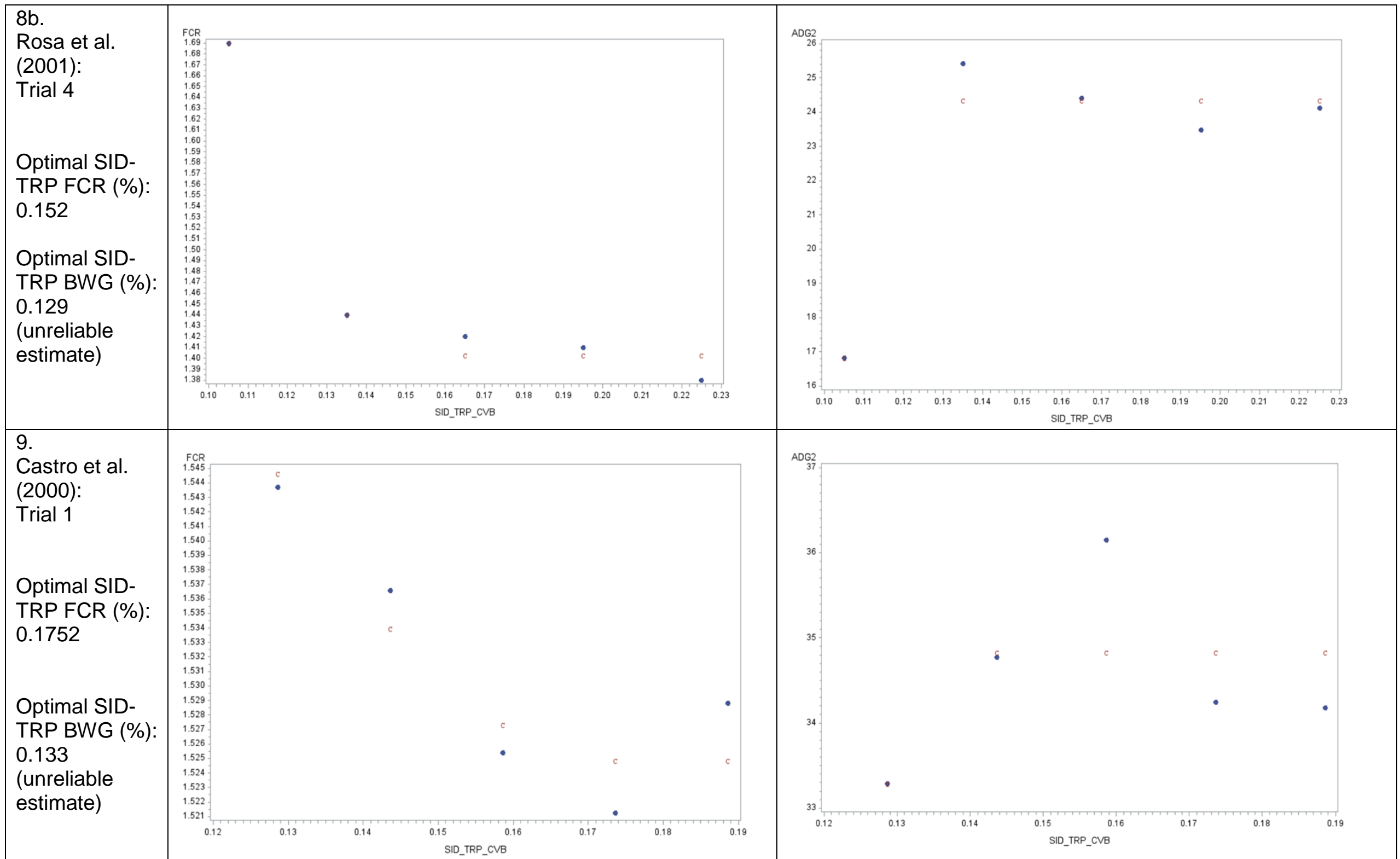




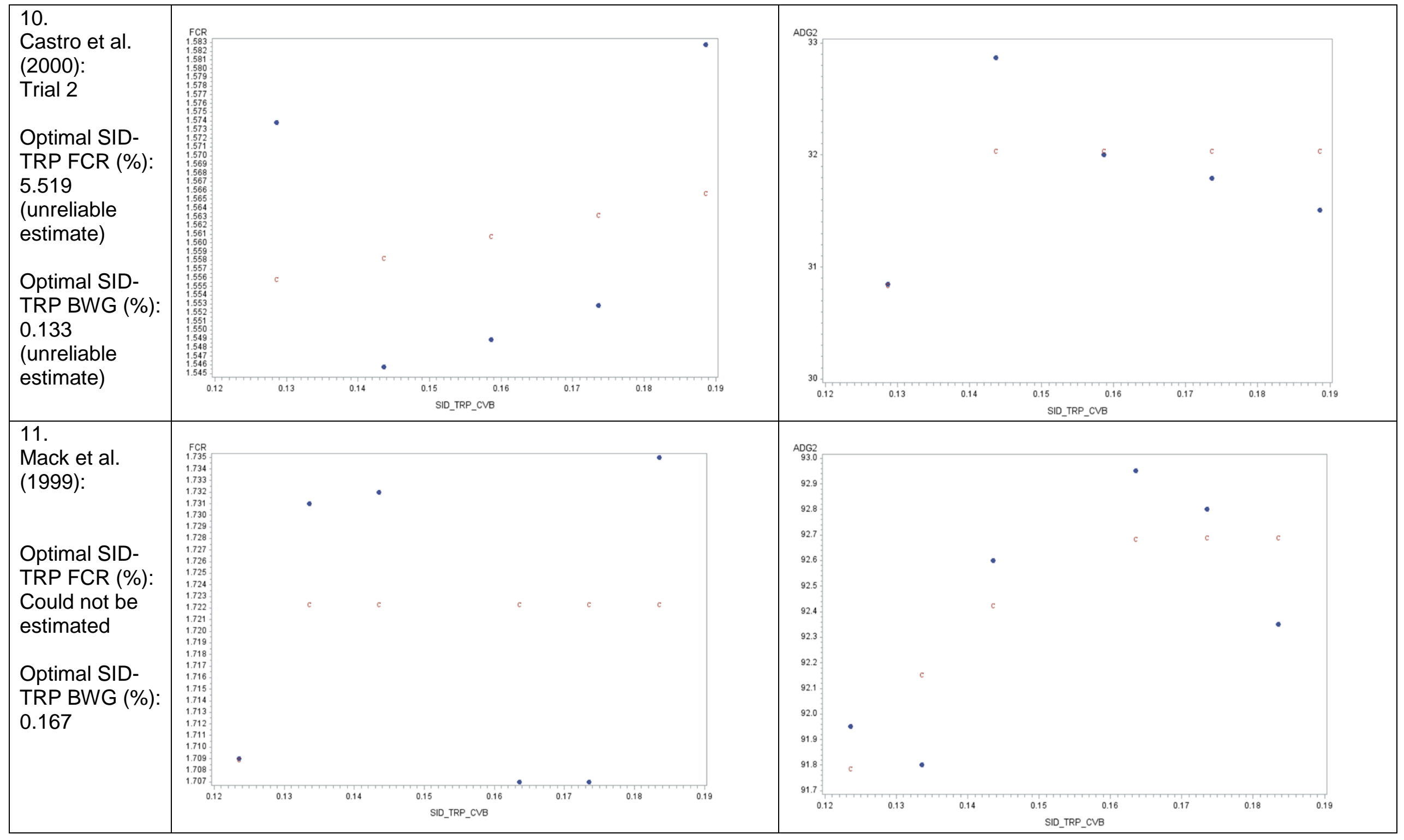




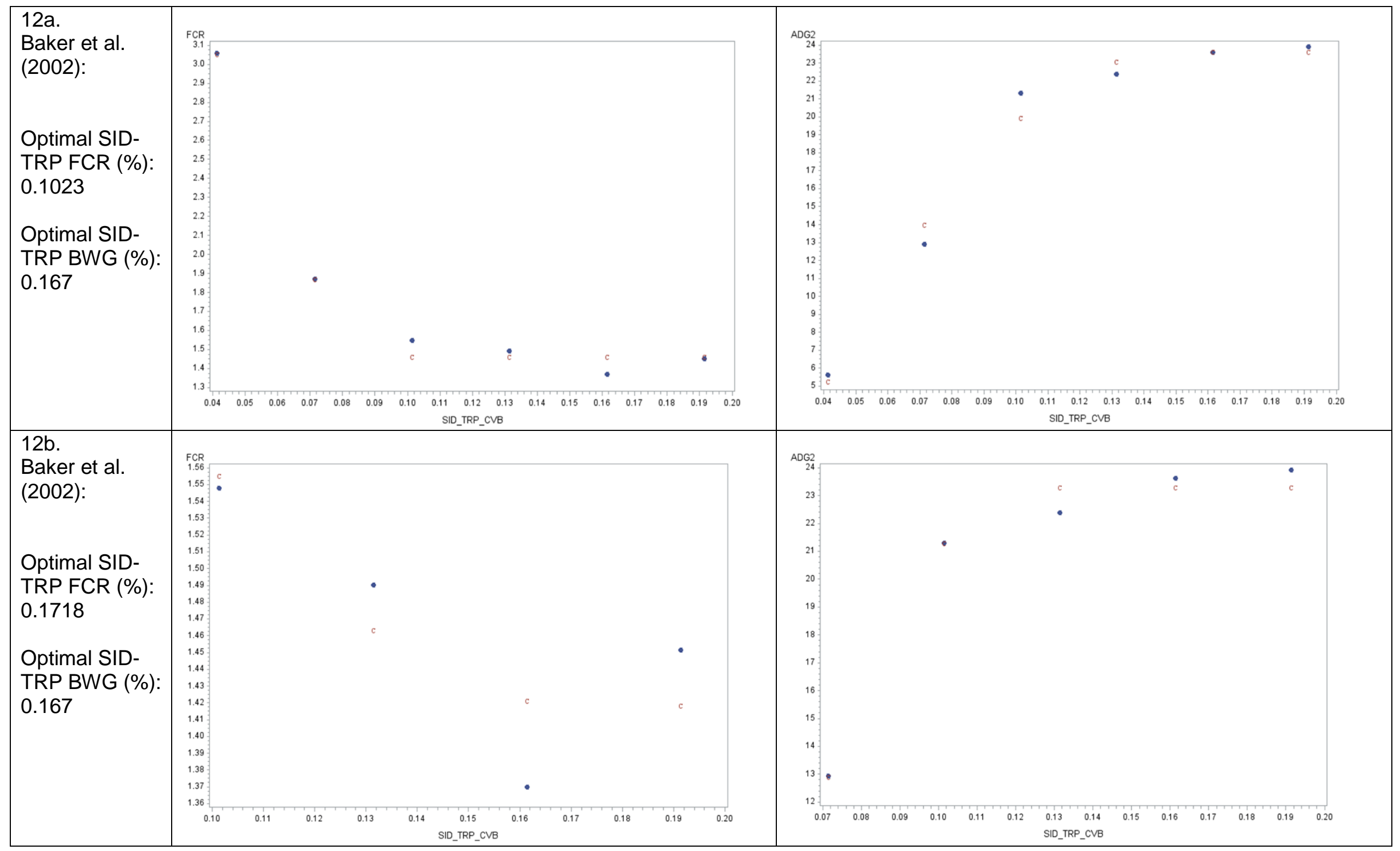




\section{Appendix B. SID-TRP model estimates using the quadratic broken-line model for minimum FCR and maximum BWG}

SID-TRP model estimates using the quadratic broken-line model for minimum FCR. The letter ' $a$ ' behind the trial number (shown in the first column) means the model is fitted on all observations whereas the letter ' $b$ ' behind the trial number (shown in the first column) means the model is fitted on all observations except the observation(s) with the lowest dietary SID-TRP level(s). If no letter is shown behind the trial number it means that the model is fitted based on all observations of the trial.

\begin{tabular}{|c|c|c|c|c|c|c|c|}
\hline Trial nr. & $\begin{array}{r}\text { Estimate } \\
\mathbf{L} \\
\end{array}$ & $\begin{array}{r}\text { Std. Err. } \\
\text { L }\end{array}$ & $\begin{array}{r}\text { Estimate } \\
\mathbf{R} \\
\end{array}$ & $\begin{array}{r}\text { Std. Err. } \\
\mathbf{R}\end{array}$ & $\begin{array}{r}\text { Estimate } \\
\mathbf{U}\end{array}$ & $\begin{array}{r}\text { Std. } \\
\text { Err. U }\end{array}$ & $\mathbf{R}^{2}$ \\
\hline $1 \mathrm{a}$ & 1.663 & 0.0507 & 0.205 & 0.0185 & 75 & 28.5 & 0.955 \\
\hline $1 b$ & 1.665 & 0.0582 & 0.200 & 0.0259 & 87 & 60.7 & 0.897 \\
\hline $2 a$ & 1.313 & 0.1779 & 0.153 & 0.0131 & 427 & 127.2 & 0.962 \\
\hline $2 b$ & 1.320 & 0.0106 & 0.155 & 0.0030 & 328 & 45.3 & 0.998 \\
\hline $3 a$ & 1.588 & 0.0382 & 0.149 & 0.0089 & 199 & 49.9 & 0.986 \\
\hline $3 b$ & 1.559 & 0.0276 & 0.180 & 0.0142 & 68 & 24.1 & 0.982 \\
\hline $4 a$ & 1.580 & 0.0072 & 0.135 & 0.0019 & 241 & 16.2 & 0.999 \\
\hline $4 b$ & 1.577 & 0.0033 & 0.141 & 0.0020 & 168 & 16.3 & 0.999 \\
\hline $5 a$ & 1.401 & 0.0260 & 0.139 & 0.0060 & 291 & 57.1 & 0.993 \\
\hline $5 b$ & 1.400 & 0.0351 & 0.141 & 0.0267 & 250 & 359.6 & 0.921 \\
\hline $6 a$ & 1.381 & 0.0121 & 0.147 & 0.0040 & 166 & 18.8 & 0.998 \\
\hline $6 b$ & 1.380 & 0.0153 & 0.149 & 0.0105 & 148 & 69.5 & 0.979 \\
\hline $7 a$ & 1.382 & 0.0201 & 0.139 & 0.0083 & 161 & 43.1 & 0.988 \\
\hline $7 b$ & 1.369 & 0.0194 & 0.173 & 0.0248 & 41 & 30.3 & 0.938 \\
\hline $8 a$ & 1.403 & 0.0096 & 0.152 & 0.0035 & 129 & 12.3 & 0.998 \\
\hline $8 b$ & 1.403 & 0.0120 & 0.152 & 0.0083 & 131 & 46.7 & 0.986 \\
\hline 9 & 1.525 & 0.0033 & 0.175 & 0.0227 & 9 & 9.0 & 0.875 \\
\hline 10 & 2.003 & 771.4000 & 5.519 & 9349 & 0 & 26.8 & 0.057 \\
\hline \multicolumn{8}{|l|}{11} \\
\hline $12 a$ & 1.464 & 0.0378 & 0.102 & 0.0063 & 429 & 93.0 & 0.992 \\
\hline $12 b$ & 1.419 & 0.0587 & 0.172 & 0.0878 & 28 & 66.7 & 0.731 \\
\hline
\end{tabular}


SID-TRP model estimates using the quadratic broken-line model for maximum BWG. The letter ' $a$ ' behind the trial number (shown in the first column) means the model is fitted on all observations whereas the letter ' $b$ ' behind the trial number (shown in the first column) means the model is fitted on all observations except the observation(s) with the lowest dietary SID-TRP level(s). If no letter is shown behind the trial number it means that the model is fitted based on all observations of the trial.

\begin{tabular}{|c|c|c|c|c|c|c|c|}
\hline Trial nr. & $\begin{array}{r}\text { Estimate } \\
L\end{array}$ & $\begin{array}{r}\text { Std. Err. } \\
\text { L }\end{array}$ & $\begin{array}{r}\text { Estimate } \\
\mathbf{R}\end{array}$ & $\begin{array}{r}\text { Std. Err. } \\
R\end{array}$ & $\begin{array}{r}\text { Estimate } \\
\mathbf{U}\end{array}$ & $\begin{array}{r}\text { Std. } \\
\text { Err. U }\end{array}$ & $\mathbf{R}^{2}$ \\
\hline $1 a$ & 28 & 0.5 & 0.191 & 0.0107 & -1606 & 412 & 0.981 \\
\hline $1 b$ & 27 & 0.1 & 0.175 & 0.0020 & -3244 & 267 & 0.999 \\
\hline $2 a$ & 48 & 4.1 & 0.238 & 0.0337 & -1474 & 517 & 0.949 \\
\hline $2 b$ & 47 & 2.1 & 0.180 & 0.0178 & -5996 & 3107 & 0.973 \\
\hline $3 a$ & 36 & 1.0 & 0.170 & 0.0104 & -2940 & 659 & 0.988 \\
\hline $3 b$ & 36 & 0.8 & 0.156 & 0.0108 & -4917 & 1928 & 0.982 \\
\hline $4 a$ & 27 & 0.6 & 0.153 & 0.0094 & -2930 & 729 & 0.987 \\
\hline $4 b$ & 27 & 0.4 & 0.140 & 0.0074 & -5837 & 2161 & 0.985 \\
\hline $5 a$ & 23 & 0.6 & 0.166 & 0.0103 & -2318 & 548 & 0.988 \\
\hline $5 b$ & 23 & 0.2 & 0.148 & 0.0034 & -5399 & 859 & 0.998 \\
\hline $6 a$ & 25 & 0.3 & 0.156 & 0.0042 & -2950 & 321 & 0.998 \\
\hline $6 b$ & 25 & 0.3 & 0.151 & 0.0081 & -3650 & 1288 & 0.987 \\
\hline $7 a$ & 25 & 0.4 & 0.149 & 0.0068 & -3353 & 634 & 0.993 \\
\hline $7 b$ & 25 & 0.3 & 0.135 & & -7812 & 713 & 0.976 \\
\hline $8 a$ & 24 & 0.7 & 0.149 & 0.0110 & -3372 & 1043 & 0.982 \\
\hline $8 b$ & 24 & 0.4 & 0.129 & ${ }^{\prime}$ & -12694 & 1523 & 0.959 \\
\hline 9 & 35 & 0.5 & 0.133 & & -71964 & 47471 & 0.434 \\
\hline 10 & 32 & 0.3 & 0.142 & & -6392 & 3516 & 0.524 \\
\hline 11 & 93 & 0.2 & 0.167 & 0.0363 & -473 & 831 & 0.643 \\
\hline $12 a$ & 24 & 0.7 & 0.150 & 0.0131 & -1557 & 383 & 0.987 \\
\hline $12 b$ & 23 & 0.5 & 0.125 & 0.0095 & -3633 & 1318 & 0.984 \\
\hline
\end{tabular}

